\title{
Penambahan Sr pada Aluminium Paduan A356 dengan Metode Lost Foam Casting (LFC)
}

\author{
Suherman $^{1 *}$, Sarjianto ${ }^{2}$ Nisfan Bahri $^{2}$, Ilmi $^{3}$, Ali Sai'in ${ }^{4}$ \\ ${ }^{1}$ Program studi Teknik Mesin Universitas Muhammadiyah Sumatera Utara \\ Jl. Kapten Muchtar Basri No.3- Medan, Sumatera Utara \\ ${ }^{2}$ Jurusan Teknik Mesin Politeknik Negeri Medan-Sumatera Utara \\ J1. Almamater No.1, Padang Bulan, Medan- Sumatera Utara \\ ${ }^{3}$ Jurusan Teknik Mesin Universitas Sumatera Utara-Medan-Sumatera Utara \\ ${ }^{4}$ Jurusan Teknik Mesin Politeknik Negeri Semarang \\ Jl. Prof. Sudarto, Tembalang, Kota Semarang, Jawa Tengah \\ *E-mail: suherman.me.umsu@gmail.com
}

Diterima: 29-04-2021; Direvisi: 28-07-2021; Dipublikasi: 27-08-2021

\begin{abstract}
Abstrak
Pemilihan proses pengecoran dan laju pendinginan sangat menentukan morfologi partikel autektik silicon yang dihasilkan pada aluminium paduan. Proses pendinginan aluminium paduan dengan metode pengecoran metode Lost Foam Casting (LFC) berjalan sedikit lambat sehingga menghasilkan sifat mekanis yang rendah. Tujuan penelitian ini adalah untuk mempelajari pengaruh penambahan modifier Sr pada aluminium A356 pada struktur mikro dan sifat mekanis dengan metode LFC. Aluminium A356 ditambahkan kedalam logam cair sesaat sebelum dituangkan kepermukaan pola polystyrene yang telah dilapisi bahan refaktori. Penambahan modifier Sr dipelajari pengaruhnya terhadap perubahan struktru mikro dan sifat mekanis (kekerasan, kekuatan impak dan kekuatan tarik). Hasil penelitian ini menunjukkan terjadinya perubahan partikel autektik silicon dari bentuk acicular ke bentuk berserabut. Nilai kekerasan, kekuatan tarik maksimum dan kekuatan impak meningkat masing-masing sebesar 27\%, 26\% dan $22 \%$ setelah penambahan.
\end{abstract}

Kata kunci: aluminium A356; modifier Sr; pengecoran LFC.

\begin{abstract}
The choice of casting process and cooling rate will determine the morphology of the authentic silicon particles produced in aluminum alloys. The cooling process of aluminum alloy with the Lost Foam Casting (LFC) method runs slowly resulting in low mechanical properties. The purpose of this study was to study the effect of adding Sr modifier to aluminum A356 on the microstructure and mechanical properties of the LFC method. the Aluminum A356 is added to the molten metal just before it is poured onto a polystyrene pattern that has been coated with a refractory material. The addition of $\mathrm{Sr}$ as modifier was studied for its effect on changes in microstructure and mechanical properties (hardness, impact strength and tensile strength). The results of this study indicate a change in the authentic silicon particles from an acicular to a fibrous form. The additional modifier Sr enhance value of hardness, maximum tensile strength and impact strength $27 \%, 26 \%$ and $22 \%$ respectively.
\end{abstract}

Keywords: Aluminium A356; modier Sr; LFC Casting

\section{Pendahuluan}

Pada satu dekade terakhir ini aluminium paduan Al-Si-Mg (A356) sangat luas penggunaannya terutama pada komponen otomotif, pesawat terbang dan industry elektronika karena memiliki beberapa kelebihan jika dibandingkan dengan paduan aluminium lainnya [1]. Paduan ini memiliki kelebihan antara lain yaitu ringan dibanding besi dan baja, tahan korosi yang baik, mudah dicor, mampu mesin dan las yang baik [1].

Pemilihan proses pengecoran serta komposisi paduan sangat mempengaruhi struktur mikro dan sifat mekanis dari aluminium paduan [2]. Banyak metode pengecoran yang digunakan dalam pembuatan komponen automotif seperti metode cetakan pasir, cetakan logam, high pressure die casting serta metode LFC [3]. Metode evaporative (lost foam casting) merupakan metode pengecoran yang sangat tepat dalam memproduksi komponen otomotif berbahan aluminium paduan. 
Pengecoran gravitasi pada paduan aluminium banyak digunakan untuk aplikasi kepala silinder untuk industri otomotif karena kemampuan cor yang baik serta sifat fisik dan mekaniknya. Baru-baru ini untuk tujuan pengurangan biaya proses pengecoran, proses die casting konvensional (CD) digantikan dengan proses pengecoran busa yang hilang (Lost Foam Casting). Karena kendala ekonomi dan persyaratan lingkungan, saat ini industri otomotif dipaksa untuk memodifikasi proses dari beberapa bagian mesin seperti kepala silinder. Saat ini, proses LFC menggantikan proses Die Casting (DC) konvensional untuk tujuan optimasi geometri, pengurangan biaya dan kontrol konsumsi [3].

Proses pengecoran LFC hanya menggunakan seperempat lebih sedikit energi dan sepertiga penggunaan logam cair daripada pengecoran [3]. Keuntungan dari proses LFC dibanding proses DC casting adalah biaya lebih rendah. Kerugian utama dari LFC adalah adanya cacat yang disebabkan oleh terjebaknya gas di logam yang membeku. Apalagi, pada proses LFC laju pendinginan proses relatif lambat dibandingkan dengan proses DC (LFC sekitar $0,8{ }^{\circ} \mathrm{C}^{\mathrm{s}-1}$ dan sekitar $30{ }^{\circ} \mathrm{C}^{\mathrm{s}-1}$ pada DC casting) [4]. Hal ini mengarah pembentukan mikrostruktur yang kasar bila diukur pada

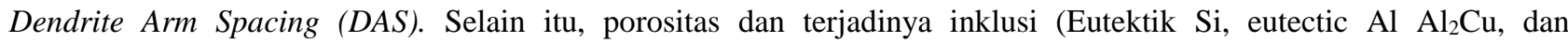
intermetallic berbasis besi) meningkat dan bergerombol. Struktur mikro Aluminium paduan yang dihasilkan oleh proses LFC dengan jaringan yang sangat kompleks dengan ukuran partikel besar: Partikel silikon, $\mathrm{Al}_{2} \mathrm{Cu}, \alpha-\mathrm{AlFeSi}, \beta-\mathrm{AlFeSi}$ dan pori-pori. Pori-pori [5] dapat memainkan peran yang menentukan di atas ukuran kritis, dengan menyediakan lokasi inisiasi retak preferensial tetapi berpengaruh dari fase lain seperti oksida [6], intermetalik besi [7] dan partikel Si [8].

Metode lost foam casting ( $L F C$ ) memiliki beberapa kelebihan yaitu keleluasaan dalam desain pola coran, tidak perlu memakai inti, bentuk yang kompleks dapat dibuat dengan teknik ini, tidak perlu finishing serta mudah dalam membuat pola [9]. Akan tetapi metode pengecoran juga memiliki banyak kekurangan seperti laju pendinginan yang lambat, banyak terbentuk porositas dan sifat mekanis yang rendah [10]. Tentunya hal ini menunjukkan sulitnya mendapatkan kekuatan mekanik yang baik aluminium cor tanpa perlakuan [11].

Beberapa peneliti telah menambahkan modifier $\mathrm{Sr}$ untuk memodikasi partikel silicon pada paduan aluminium. Uludag dkk. [12] meneliti penambahan Sr pada aluminium paduan meningkatkan potensi terjadinya retak panas (hot tearing). Mereka menemukan lapisan bifilm sebagai penyebab utama terjadinya retak panas pada cairan logam dan coran. Tidak mudah untuk menemukan lapisan bifilm mungkin berakhir di rongga cetakan. Oleh karena itu, lebih sulit untuk memperkirakan apakah retak panas dapat terjadi atau tidak. Namun demikian, mereka bertindak sebagai nukleasi heterogen untuk cairan untuk memisahkan dan dengan demikian meningkatkan robekan panas. Penambahan modifier $\mathrm{Sr}$ pada aluminium paduan mengurangi ukuran partikel autektik silicon [11,12] akan tetapi meningkatkan jumlah porositas karena penambahan modifier $\mathrm{Sr}$ meningkatkan kandungan hydrogen dalam logam cair sehingga berujung pada pembentukan porositas berbentuk bulat $[11,12,13]$. Penambahan Sr pada aluminium paduan meningkatkan kekuatan tarik dan kekerasan hasil coran, hal ini karena modifer $\mathrm{Sr}$ menghasilkan ukuran dendrite arm spacing (SDAS) pada logam cor dan memperkecil ukuran partikel pase $\beta$ (silicon) sebagaimana yang dilaporkan [14, 15]. Ozturk, dkk [16] menemukan bahwa penambahan Sr juga meningkatkan ketahanan korosi pada paduan aluminium A356.

Oleh karena itu dengan penambahan $\mathrm{Sr}$ sebesar 0,01\% akan mampu merubah morfologi partikel silikon eutektik dan ukuran denrite arm spacing (DAS), bentuk plat ke bentuk berserabut sehingga dapat meningkatkan sifat mekanis (mechanical properties) seperti kekerasan dan kekuatan tarik dan kekuatan impak aluminium paduan Al-Si-Mg (A356) yang digunakan untuk membuat komponen automotif seperti kepala silinder motor 2 tak.

\section{Material dan metodologi}

Pada penelitian ini menggunakan aluminium paduan A356 berbentuk ingot dengan uji komposisi menggunakan spectrometer analisis yaitu 7,70Si-0,36Fe-0,01Cu-0,37Mg-0,13Zn-0,29Ti-0,02Pb. Penelitian ini dimulai dengan 
Suherman dkk /Jurnal Rekayasa Mesin p-ISSN: 1411-6863, e-ISSN: 2540-7678

Vol.16|No.2|249-254|Agustus|2021

mempersiapkan pola polystyrene/ Styrofoam yang dibentuk mengikuti ukuran seperti Gambar (1). Styrofoam lembaran dengan densitas $20 \mathrm{~kg} / \mathrm{m}^{3}$ dengan memotong dengan pemotong elektrik. Pola prototipe kepala silinder sepeda motor 2 tak selanjutnya dirangkai dengan saluran turun dengan lem Styrofoam dan dimasukkan kedalam cairan bahan ceramic untuk melapisi pola agar lebih kaku yang merupakan campuran Colloidall Silica $\left(\mathrm{O}_{2} \mathrm{Si}\right)$ dan Zircon Oxide $\left(\mathrm{ZrO}_{2}\right)$, pola yang sudah dilapisi bahan keramik terlebih dibiarkan mengering pada temperature kamar seperti penelitian yang telah dilakukan [9]. Pola kemudian ditanam kedalam pasir silica berukuran mesh 40-60 hingga menutupi seluruh pola. Aluminium paduan A356 dilebur dalam dapur krusibel dan ditambahkan master alloy Al-10Sr-1B sesaat sebelum dituang. Penuangan logam cair dilakukan pada permukaan pola pada temperature $730{ }^{\circ} \mathrm{C}$. Hasil coran prototype kepala silinder kemudian dipotong untuk membuat specimen uji tarik mengikuti standar ASTM E-801 dan specimen uji impak mengikuti standar ASTM E-23. Pengamatan stuktur mikro dipersiapkan dengan mempolis spesimen menggunakan mesin polishing dan selanjutnya diamati menggunakan mikroskop optik metalurgi.

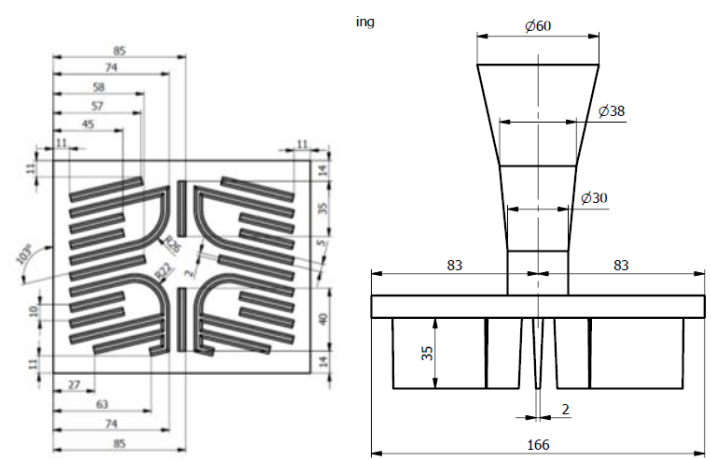

Gambar 1. (a) Pandangan atas pada dimensi pola sirip-sirip pada head silinder, (b) pandangan samping saluran turun

\section{Hasil dan pembahasan}

A. Mikrostruktur

Gambar 2 menunjukkan hasil pengamatan struktur mikro aluminium paduan A356 dengan dan tanpa penambahan Sr. Proses pengecoran aluminium paduan A356 menggunakan metode Evaporative memberikan pendinginan yang relatif lambat sehingga menghasilkan ukuran partikel silikon yang sedikit kasar [3] ukuran rata-rata $45 \mu \mathrm{m}$ dengan bentuk plat berujung runcing (gambar 2 a dan b). Partikel silicon tersebar merata keseluruh bagian aluminium (berwarna gelap), jumlah persentase silicon pada aluminium silikon tentunya juga akan mempengaruhi dari sifat mekanis (kekuatan tarik maksimum, ketangguhan dan kekerasan) pada aluminium paduan.

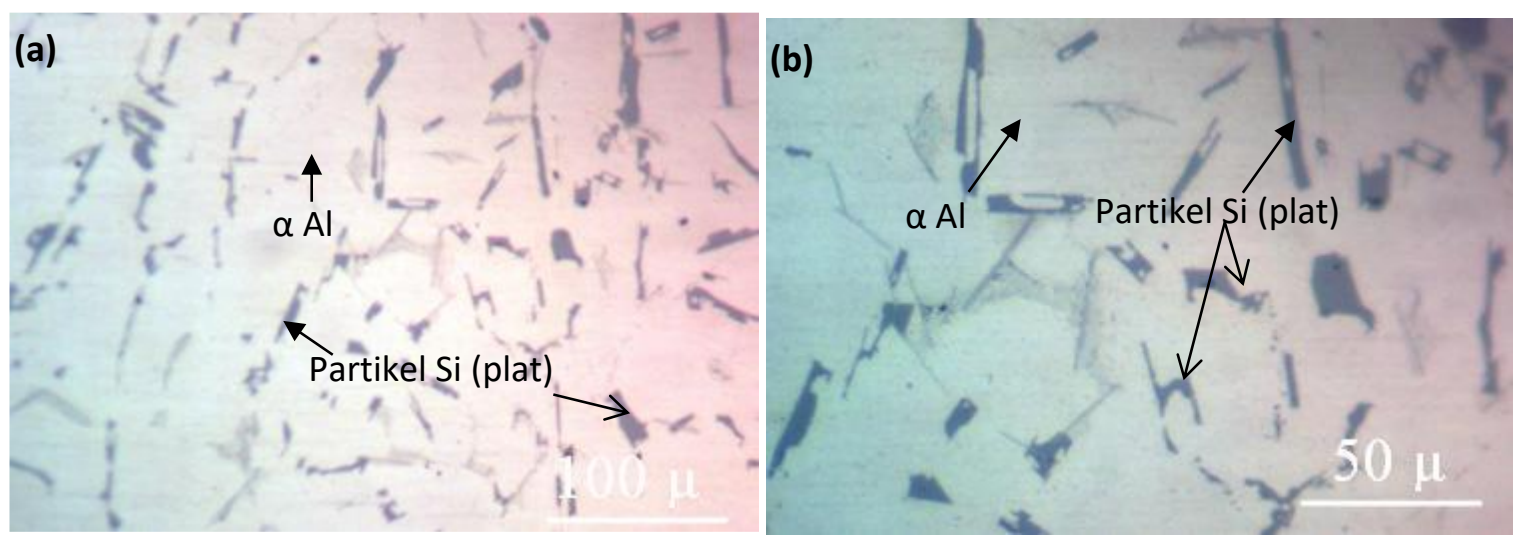

Gambar 2. foto mikro (a) aluminium A356 200x, (b) ) aluminium A356 400x,

Penambahan Sr sebesar 0,01\% kedalam aluminium paduan A356 merubah bentuk partikel autektik silicon Aluminium paduan A356 setelah penambahan Sr berubah menjadi bentuk berserabut (fibrous) [11,14,17], hal ini sesuai dengan penelitian dimana partikel autektik silicon tersebar diantara dendrit aluminium. Penambahan $\mathrm{Sr}$ juga 
Suherman dkk /Jurnal Rekayasa Mesin p-ISSN: 1411-6863, e-ISSN: 2540-7678

Vol.16|No.2|249-254|Agustus|2021

mengakibatkan turunnya temperature autektik [16] dan butir $\alpha$-aluminium terhadap laju pendinginan (cooling rate) [17] sehingga hal ini mengurangi ukuran partikel autektik silikon.
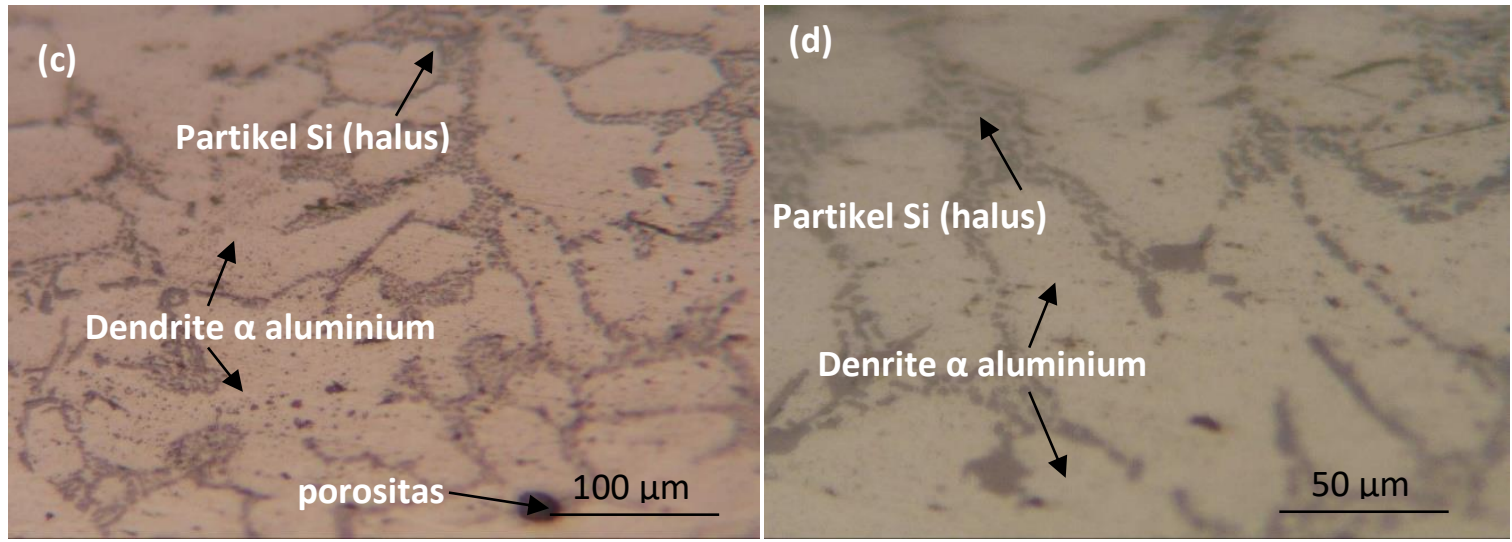

Gambar 3. foto mikro (c) aluminium A356 dengan penambahan Sr 200x dan (d) ) aluminium A356 penambahan $\mathrm{Sr}$ $400 \mathrm{x}$

Proses pengecoran metode LFC menyebabkan peningkatan kandungan hydrogen sehingga banyak terjadinya porositas (gambar 2.c) hasil coran karena sebagian besar polystyrene yang terbakar akan membentuk gas dan keluar melalui celah pasir silika, akan tetapi sebagian kecil akan tertinggal pada permukaan logam coran hal ini sesuai dengan penelitian Suherman, dkk [15]. Selain itu Penambahan Sr pada logam cair biasanya memberikan efek terhadap bertambahnya kandungan hidrogen dan kerentanan terjadinya porositas pada logam Sifat Mekanis Aluminium A356 [12]. Penambahan modifier Sr meningkatkan kekuatan tarik maksimum pada aluminium paduan seperti disajikan pada tabel (1), peningkatan kekuatan tarik maksimum sebesar 26\% dari 115 Mpa menjadi 143 Mpa $[18,19]$. Penambahan Sr pada aluminium paduan mempengaruhi kekuatan tarik maksimum $[11,19]$, selain itu juga bentuk permukaan hasil uji tarik bersifat patah ulet [11].

Tabel 1. Sifat Mekanis Aluminium Paduan A356 [20]

\begin{tabular}{lccc}
\multicolumn{1}{c}{ Material } & $\begin{array}{c}\text { Kekuatan Tarik Maks } \\
\text { (MPa) }\end{array}$ & Kekerasan (BHN) & $\begin{array}{c}\text { Kekuatan Impak } \\
\text { (Joule) }\end{array}$ \\
\hline A356 & 115 & 45 & 45 \\
A356 $+\mathrm{Sr}$ & 145 & 57 & 55 \\
\hline
\end{tabular}

Nilai kekerasan aluminium paduan A356 dengan penambahan $\mathrm{Sr}$ (57 BHN) lebih tinggi dari dari aluminium paduan A356 dengan metode pengecoran LFC [19, 21]. Nilai peningkatan kekerasan sebesar 27\% dimana berkaitan dengan pengurangan ukuran DAS [19] dan juga terjadi pengecilan ukuran partikel autektik silikon yang tersebar pada aluminium paduan [22]. Kekuatan impak mengalami peningkatan sebesar 22\% setelah penambahan modifier Sr pada aluminium paduan A356 (tabel 1), peningkatan kekuatan impak karena terjadinya perubahan pada partikel autektik silikon dari bentuk plat ke bentuk berserabut (fibrous) sehingga menyebabkan hasil coran lebih tangguh.

\section{Kesimpulan}

Penambahan Sr sebagai modifier sebesar 0,01\% pada aluminium paduan A356 menghasilkan perubahan pada struktur mikro yang menghasilkan perubahan pada partikel autektik silicon dari bentuk plat (platlike) ke bentuk berserabut (fibrous).Nilai kekerasan coran meningkat sebesar sebesar $27 \%$ setelah penambahan Sr, sedangkan nilai kekuatan 
Suherman dkk /Jurnal Rekayasa Mesin p-ISSN: 1411-6863, e-ISSN: 2540-7678

Vol.16|No.2|249-254|Agustus|2021

impak juga meningkat sebesar $22 \%$ dari $45 \mathrm{~J}$ menjadi $55 \mathrm{~J}$. penambahan modifier $\mathrm{Sr}$ mengurangi ukuran SDAS sehingga meningkatkan kekuatan tarik sebesar 26\% dari 115 MPa menjadi 145 Mpa.

\section{Daftar Pustaka}

[1] 'Surdia, T. dan Saito, S., 1992, 'Pengetahuan Bahan Teknik', P.T Pradnya Paramitha, Jakarta.

[2] S. Sun, B. Yuan, and M. Liu, "Effects of moulding sands and wall thickness on microstructure and mechanical properties of Sr-modified A356 aluminum casting alloy," Transactions of Nonferrous Metals Society of China, vol. 22, no. 8, pp. 1884-1890, Aug. 2012, doi: 10.1016/S1003-6326(11)61402-7.

[3] "Buku Pengecoran Logam (Metode Evaporative) - Deepublish | Penerbit Buku Deepublish." https://penerbitbukudeepublish.com/shop/buku-pengecoran-logam/ (accessed Sep. 23, 2019).

[4] S. Tabibian, E. Charkaluk, A. Constantinescu, A. Oudin, and F. Szmytka, "Behavior, damage and fatigue life assessment of lost foam casting aluminum alloys under thermo-mechanical fatigue conditions," Procedia Engineering, vol. 2, no. 1, pp. 1145-1154, Apr. 2010, doi: 10.1016/j.proeng.2010.03.124.

[5] X. Cao and J. Campbell, "The nucleation of Fe-Rich phases on oxide films in Al-11.5Si-0.4Mg cast alloys," Metall. Mater. Trans. A, vol. 34, no. 7, pp. 1409-1420, Jul. 2003.

[6] X. Cao and J. Campbell, "The nucleation of Fe-Rich phases on oxide films in Al-11.5Si-0.4Mg cast alloys," Metall and Mat Trans A, vol. 34, no. 7, pp. 1409-1420, Jul. 2003, doi: 10.1007/s11661-003-0253-3.

[7] Buffière, J.-Y., Savelli, S., Jouneau, P.H., Maire, E., Fougères, R, 2001. Experimental study of porosity and its relation to fatigue mechanisms of model $\mathrm{Al}-\mathrm{Si} 7-\mathrm{MgO} .3$ cast $\mathrm{Al}$ alloys |

[8] M. Uludağ, R. Çetin, D. Dispinar, and M. Tiryakioğlu, "The effects of degassing, grain refinement \& Sr-addition on melt quality-hot tear sensitivity relationships in cast A380 aluminum alloy," Eng. Fail. Anal., vol. 90, pp. 90102, Aug. 2018.

[9] Suherman dan Syahputra, "PENGARUH PENAMBAHAN CU DAN SOLUTION TREATMENT TERHADAP SIFAT MEKANIS DAN STRUKTUR MIKRO PADA ALUMINIUM PADUAN A356,” p. 7, 2014.

[10] S. Mizhar, "Pengaruh Heat Treatment Terhadap Struktur Mikro dan Kekerasan Aluminium Paduan Al-Si-Cu Pada Cylinder Head Sepeda Motor,” vol. 3, no. 1, p. 7, 2016.

[11] S. Suherman, A. Syakura, A. Nasution, S. Mizhar, O. Hermawan, and A. Handoko, "Influence of Additional Sr and TiB on Aluminium Al-Si-Cu-Mg Alloys for Produced Prototype Cylinder Head Motorcycle," Proceeding of Ocean, Mechanical and Aerospace-Science and Engineering-, vol. 5, no. 1, pp. 79-83, 2018.

[12] M. Uludağ, R. Çetin, D. Dispinar, and M. Tiryakioğlu, "The effects of degassing, grain refinement \& Sr-addition on melt quality-hot tear sensitivity relationships in cast A380 aluminum alloy," Engineering Failure Analysis, vol. 90, pp. 90-102, Aug. 2018, doi: 10.1016/j.engfailanal.2018.03.025.

[13] G. Timelli, D. Caliari, and J. Rakhmonov, "Influence of Process Parameters and Sr Addition on the Microstructure and Casting Defects of LPDC A356 Alloy for Engine Blocks," Journal of Materials Science \& Technology, vol. 32, no. 6, pp. 515-523, Jun. 2016, doi: 10.1016/j.jmst.2016.03.010.

[14] M. F. Ibrahim, S. A. Alkahtani, Kh. A. Abuhasel, and F. H. Samuel, "Effect of intermetallics on the microstructure and tensile properties of aluminum based alloys: Role of $\mathrm{Sr}, \mathrm{Mg}$ and Be addition," Materials \& Design, vol. 86, pp. 30-40, Dec. 2015, doi: 10.1016/j.matdes.2015.07.019.

[15] Suherman dan Handoko, A, "Influence of Additional Sr and TiB on Aluminium Al-Si-Cu- Mg Alloys for Produced Prototype Cylinder Head Motorcycle,”. Vol., p. 5, 2012. 
Suherman dkk /Jurnal Rekayasa Mesin p-ISSN: 1411-6863, e-ISSN: 2540-7678

Vol.16|No.2|249-254|Agustus|2021

[16] İ. Öztürk, G. Hapçı Ağaoğlu, E. Erzi, D. Dispinar, and G. Orhan, "Effects of strontium addition on the microstructure and corrosion behavior of A356 aluminum alloy," Journal of Alloys and Compounds, vol. 763, pp. 384-391, Sep. 2018, doi: 10.1016/j.jallcom.2018.05.341.

[17] Q. Liu et al., "Effects of $\mathrm{Sr}, \mathrm{Ce}$ and $\mathrm{P}$ on the microstructure and mechanical properties of rapidly solidified $\mathrm{Al} 7 \mathrm{Si}$ alloys," Materials Characterization, vol. 140, pp. 290-298, Jun. 2018, doi: 10.1016/j.matchar.2018.04.018.

[18] M. Faccoli, D. Dioni, S. Cecchel, G. Cornacchia, and A. Panvini, "Optimization of heat treatment of gravity cast Sr-modified B356 aluminum alloy," Transactions of Nonferrous Metals Society of China, vol. 27, no. 8, pp. 1698-1706, Aug. 2017, doi: 10.1016/S1003-6326(17)60192-4.

[19] P. Tang, W. Li, Y. Zhao, K. Wang, W. Li, and F. Zhan, "Influence of strontium and lanthanum simultaneous addition on microstructure and mechanical properties of the secondary Al-Si-Cu-Fe alloy," Journal of Rare Earths, vol. 35, no. 5, pp. 485-493, May 2017, doi: 10.1016/S1002-0721(17)60938-4.

[20] "Pengaruh Penambahan Sr atau TiB Terhadap Struktur Mikro dan Fluiditas Pada Paduan Al-6\%Si-0,7\%Fe," no. 4, p. 5, 2009.

[21] Q. Liu et al., "Effects of $\mathrm{Sr}, \mathrm{Ce}$ and $\mathrm{P}$ on the microstructure and mechanical properties of rapidly solidified $\mathrm{Al} 7 \mathrm{Si}$ alloys," Materials Characterization, vol. 140, pp. 290-298, Jun. 2018, doi: 10.1016/j.matchar.2018.04.018.

[22] G. Timelli, D. Caliari, and J. Rakhmonov, "Influence of Process Parameters and Sr Addition on the Microstructure and Casting Defects of LPDC A356 Alloy for Engine Blocks," Journal of Materials Science \& Technology, vol. 32, no. 6, pp. 515-523, Jun. 2016, doi: 10.1016/j.jmst.2016.03.010. 